\title{
Tips for Delivering Effective Presentations ${ }^{1}$
}

\author{
Brianna Shanholtzer, Andrew C. Thoron, and J. C. Bunch ${ }^{2}$
}

\section{Introduction}

At some point, most people are faced with the daunting task of delivering a presentation. These presentations could be required by job responsibilities, as an academic assignment, or in roles within the community. Presentations may be delivered to small or large audiences. Giving a presentation in front of an audience may be a frightening endeavor; however, by following five steps, you can make the task of giving a presentation easier and ensure that your presentation will be effective.

\section{What is an effective presentation?}

An effective presentation meets the objectives set for it (Nickols, 2003), and a presentation's effectiveness is often determined by the relationship between the presenter and the audience (University of Leicester, 2017). To help build this relationship, the presenter should prepare ahead of time and consider the needs, interests, and goals of the audience. Effective presentations have clear objectives, purpose, and flow (University of Leicester, 2017). The five factors to an effective presentation are: (a) confidence, passion, and enthusiasm about the topic; (b) use of proper visual aids; (c) use of stories or examples to engage the audience; (d) an interactive atmosphere established through questioning; and (e) effective speaking skills.

\section{Confidence, Passion, and Enthusiasm About the Topic}

Step one is the ability of the presenter to be confident, passionate, and enthusiastic about the topic. If you are not confident in yourself and your presentation, your audience will be able to tell! In order to gain confidence in the presentation and your presentation skills, practice and preparation are important, but not to the point of sounding too rehearsed. Practicing alone and in front of others is vitally important. It is equally as important to include gestures and pauses while practicing your presentation. Passion and enthusiasm for your topic is crucial. Energy and enthusiasm will transfer to your audience.

\section{Use of Proper Visual Aids}

The use of visual aids can add to your presentation and can engage your audience by helping to improve an audience's memory and understanding of your topic ("Using Visual Aids," 2015). Visual aids may include electronic slides, charts, graphs, photographs, people, and many other creative aids. These aids can also serve as notes for the presenter and can help you remain on task. However, it is important to remember that a visual aid should be used as an aid and not as a crutch. No matter which visual aid you choose to use, it is vital to use it properly and to assure the visual aid is appropriate and fits the context of the topic. The following are some simple rules to make sure you are using your visual aid properly ("Using Visual Aids," 2015):

1. This document is AEC674, one of a series of the Department of Agricultural Education and Communication, UF/IFAS Extension. Original publication date November 2019. Visit the EDIS website at https://edis.ifas.ufl.edu for the currently supported version of this publication.

2. Brianna Shanholtzer, graduate assistant; Andrew C. Thoron, associate professor; and J. C. Bunch, associate professor, Department of Agricultural Education and Communication; UF/IFAS Extension, Gainesville, FL 32611.

The Institute of Food and Agricultural Sciences (IFAS) is an Equal Opportunity Institution authorized to provide research, educational information and other services

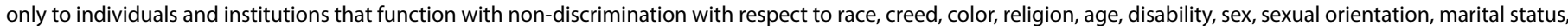

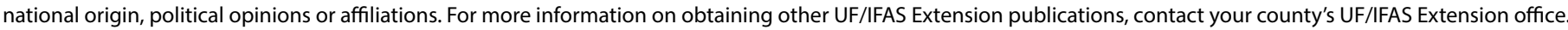
U.S. Department of Agriculture, UF/IFAS Extension Service, University of Florida, IFAS, Florida A \& M University Cooperative Extension Program, and Boards of County Commissioners Cooperating. Nick T. Place, dean for UF/IFAS Extension. 


\section{Make sure you are standing to the side of your visual} aid. Your audience should have a clear view of your visual aid. If your audience cannot see your visual aid without obstruction, then it is not serving its purpose.

2. Practice makes perfect! Earlier it was stated that practicing your delivery is important. It is just as important to practice with your visual aids.

3. Can the audience see this? When using a visual aid, your audience should not only have a clear view of the visual aid, but they should also be able to see it easily. This is especially important when presenting information in tables and/or graphs. Make sure fonts on your slides are large enough. When selecting the size of the font, room size should be taken into consideration. Pick a font that is easy to read. Keep your visual aids simple. A good rule when deciding how much to add to a slide is the $6 \times 6$ rule. This rule suggests that your slide should have no more than 6 words across and 6 points down on the slide. Finally, make sure that any colors on your visual aids are bold enough to read and complement each other well.

\section{Point out key elements in your visual aid. If there is} something extremely important in one of your visual aids, make sure you point this out to your audience. When looking at a chart, your audience may need to be directed to the specific part of the chart that you are referencing.

5. Smooth transitions. When moving from your presentation to your visual aid, ensure the transition is smooth. The use of the visual aid should flow naturally with your presentation. The flow from one slide to another should also be a natural progression. The visual aid should add to your presentation, not distract from it.

\section{Use of Stories or Examples to Engage the Audience}

Think about the most memorable presentation that you have attended. What were some key elements of this presentation? Chances are that during this presentation the presenter made sure to keep you engaged at all times. The speaker probably used many stories and examples during their presentation. Using stories or examples can aid in making a presentation more personable, which in turn can help your audience relate to you as a presenter. It is important that the story fit the context and describe or help illustrate a key point of your presentation. The presenter should also consider if the story will be relatable to their audience. They should take into account the cultural background of their audience and whether the story they tell is culturally relevant. Examples and stories help the audience relate their experiences to your story and thus build rapport and credibility. This will help the audience remember your key points long after your presentation is complete.

\section{Good Example of Using Examples and Storytelling}

Mary is presenting to an audience of high school students about advocating for the agricultural industry. At the beginning of her presentation, Mary shares with the audience a time when she was asked in an elevator what she does for a living. Mary responded, "I'm a dairy farmer." Mary then briefly explained to the individual what a day in her life looks like. She also mentioned that it is important to her to treat her animals well and provide them with the best life possible. Her story lasts about two minutes.

\section{Poor Example of Using Examples and Storytelling}

Mary is presenting to an audience of high school students about advocating for the agricultural industry. At the beginning of her presentation Mary shares with the audience a time when she was asked in an elevator what she does for a living. Mary describes to the audience what she was doing that day prior to getting on the elevator, what she was wearing, the weather outside, what she ate for breakfast and lunch that day, and how she was running behind for her doctor's appointment before getting on the elevator. Finally, Mary shares with the audience how she responded to the individual on the elevator. Mary responded, "I am a dairy farmer." Mary then briefly explained to the individual what a day in her life looks like. She also mentioned that it is important to her to treat her animals well and provide them with the best life possible. Mary then continues to share with the audience what happened during the rest of her day. She shares what she had for dinner that night, that she stopped for gas on the way home, and that she was able to catch her favorite TV show before heading to bed. Mary's story lasts about 10 minutes. Mary's key message gets lost in an ocean of irrelevant information. Use the time and attention span of your audience wisely.

\section{Invite an Interactive Atmosphere Through Questioning}

The ultimate form of engagement between a presenter and their audience is through questioning. However, most presenters fail to ask their audience questions. Many presenters are intimidated by individuals not answering their question at all or simply by coming up with a question 
to ask (Mitchell, n.d.). Many individuals struggle with how to integrate or incorporate questioning their audience throughout their presentation naturally. Here are a few suggestions when it comes to asking questions (Cotton, 1988):

\section{Start with an easy question, then proceed to more} challenging questions. By starting with harder questions, you may scare off individuals from wanting to try to answer your next question.

\section{Plan a few questions prior to your presentation. When} practicing your presentation think of a few questions that you may want to ask your audience at certain points. Write these questions down, and continue to practice them in your presentation.

\section{Signal your question to your audience. It is important} for your audience to know that you want them to respond to your question. An easy way to do this is by simply saying, "Here is a question for you..."

\section{Ask your question slowly, clearly, and loudly enough} for the entire group to hear. This is vital. Your audience cannot respond to your question if they cannot understand what you were saying.

5. Wait for answers. Do not call on the first person to put their hand up as soon as they do. This does not give enough time for others to think about their answer to the question. It is important to give everyone time to process how they would respond to your question. It is suggested that you wait for at least 3 seconds after asking your question for audience members to respond (Rowe, 1986). Do not be afraid of silence after asking a question. This could mean that the audience is actually thinking about the question that you asked. If the silence prolongs, you may need to rephrase the question.

6. Do not humiliate anyone. This is key! It is important to acknowledge every answer that you get. A simple "thank you" is enough. If someone has a wrong answer, that is okay. Simply state, "That is not exactly what I was looking for, but I can see how you may think that."

\section{Use Effective Speaking Skills}

The importance of practicing your presentation has already been mentioned. However, it is just as important to practice your speaking skills. Using effective speaking skills can help your message get across to your audience more easily.
1. Grab the attention of your audience within the first 30 seconds of your presentation. Speaking tone and volume at the beginning or introduction is important to grab attention. Other ways to grab attention are through questions or visual aids. Further, it is just as important to close your presentation with a dynamic ending that will leave your audience with a great impression (North, n.d.). A dynamic ending would involve reminding your audience of the key points of your speech and include something to engage your audience in your conclusion. Some examples would be telling the end of a story that you included in your speech, telling a joke, revealing a key component of your presentations that you set up to be revealed at the end, or even engaging the audience in the conclusion by having them share what they learned during your presentation. Make sure to focus on making these parts of your presentation particularly strong and practicing them.

2. Make eye contact with your audience. Making eye contact helps you connect with certain individuals. If you know the names of those individuals, use them as well (Storz, 2002).

\section{Put emphasis on certain words that you want to stand} out. Emphasis can help your audience key in on important words. One way that this can be done is through pausing after important terms. By taking a moment to pause, it gives your audience a moment to take in what you said (Storz, 2002).

4. Do not read your presentation. Reading your entire presentation can distract from your message because the audience will be less inclined to listen to you and simply read your content. However, it is important to use an outline. Looking at your outline can help you remember what part of your presentation you are on. Outlines should only act as a guide to keep you and the audience on-track and allow them to see a road map of your talking points (Storz, 2002).

5. Use full sentences and correct grammar. During your presentation, keep in mind basic grammar rules. This adds to your credibility as a presenter. Use full and complete sentences when presenting to an audience (Storz, 2002).

6. Use nonverbal communication. Nonverbal communication, such as hand gestures, body language, and facial expressions, is a key component to any presentation. Sometimes your audience will notice these elements of your presentation just as much as the words you use 
during the presentation (Mitchell, n.d.). It is important to add in some nonverbal communication to aid your presentation. However, be careful not to overdo this and distract from your message. Presenters should also learn how to control their nonverbal communication when the audience member is answering a question. Done poorly, these nonverbal cues could potentially shut down a verbal exchange, but done well, they could lead the conversation to productive new paths.

\section{Conclusion}

Through application of the practices discussed in this article, individuals will be able to deliver more effective presentations. Focusing on the five main concepts described in this article will help individuals improve their public-speaking skills. Demonstrating confidence, passion, and enthusiasm in delivering the subject matter, using proper visual aids, using stories or examples to engage their audience, inviting an interactive atmosphere through questioning, and using basic effective speaking skills will greatly enhance the presenter's ability to better communicate with their audience.

\section{References}

Cotton, K. (1988). Classroom questioning. North West Regional Education Laboratory. Retrieved from http:// www.learner.org/workshops/socialstudies/pdf/session6/6. ClassroomQuestioning.pdf

Mitchell, O. (n.d.). The 10 steps to asking questions so you get an answer every time. Retrieved from https://speakingaboutpresenting.com/audience/asking-questions-audience/

Nickols, F. (2003). Effective Presentations. Retrieved from https://www.nickols.us/presentations.pdf

North, M. L. (2016, November 03). 10 Tips for Improving your Public Speaking Skills. Harvard Professional Development. Retrieved from https://www. extension.harvard.edu/professional-development/ blog/10-tips-improving-your-public-speaking-skills

Rowe, M. B. (1986). Wait time: Slowing down may be a way of speeding up! Journal of Teacher Education, 37(1), 43-50. doi:10.1177/002248718603700110

Storz, C. (2002). Oral presentation skills, a practical guide. Retrieved from https://www.academia.edu/5239769/ ORAL_PRESENTATION_SKILLS_A_PRACTICAL_GUIDE
University of Leicester. (2017, March 17). Planning an effective presentation. Retrieved from https://www2.le.ac.uk/ offices/ld/resources/presentations/planning-presentation

Using Visual Aids. (2015). Retrieved from https://www. comm.pitt.edu/visual-aids 